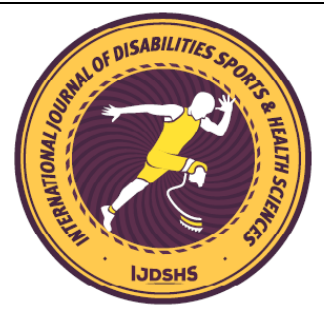

\title{
Relationship of Hand Grip Strength on The Upper Extremity Function, Activities of Daily Living and Physical Activity Level in Patients with Postmastectomy Lymphedema: A Pilot Study
}

\author{
Ozlem UCEL* ${ }^{1 \text { iD }}$, Filiz EYUBOGLU ${ }^{2}$ and Ayse Reyhan CELIKER ${ }^{3}$ (iD \\ ${ }^{* 1}$ Acıbadem Maslak Hospital, Senology Research Institute, Lymphedema Treatment Center, Istanbul \\ ${ }^{2}$ Department of Physiotherapy and Rehabilitation, Uskudar University Faculty of Health Sciences, Istanbul \\ *Corresponding author: ozlem.ucel@acibadem.com
}

\begin{abstract}
This study aimed to investigate the relationship of hand grip strength on upper extremity functionality, activities of daily living, and physical activity level in female patients with lymphedema who have undergone breast cancer surgery. A total of 15 female patients with a diagnosis of lymphedema associated with breast cancer treatment were included in the study. The presence and severity of lymphedema were determined by circumference measurement. A hand dynamometer was used to evaluate the hand grip strength. Disabilities of Arm, Shoulder and Hand Questionnaire (DASH); Milliken Activities of Daily Living Scale (MAS); and the long form of the International Physical Activity Questionnaire(IPAQ) were used to evaluate upper extremity functionality, daily living activity, and physical activity level, respectively. The mean age of the patients was $51 \pm 10.6$ years. DASH score was significantly related with age (r:0.639; p:0,010). The relationship between the hand grip strength of the affected side and the hand grip strength of the unaffected side was statistically positively significant (r:0.756; p:0.001).It was determined that hand grip strength was related to the total MAS value and the DASH score (r:0.609;p:0.016 and r:-0.624; p:0.013, respectively). The relationship between postoperative lymphedema development time with affected side hand grip strength and total MAS score was statistically significant (r:0.574; p:0.025 and r:0.766; p:0.001, respectively). There were no correlations between IPAQ score and hand grip strength, DASH, and MAS values ( $p>0.05)$. Considering these results, we concluded that improving hand grip strength in the early period may increase upper extremity functionality and quality of life for these patients.
\end{abstract}

Keywords

Breast Cancer, Lymphedema, Hand Grip Strength, Activities Of Daily Living, Physical Activity

\section{INTRODUCTION}

Breast cancer is the most common malignancy in women and it has better survival rates than other cancers (Hayes et al. 2005). Lymphedema is defined as a disease that occurs as a result of the accumulation of water, plasma proteins, extravascular fluid, and parenchymal cells in the interstitial space due to the low carrying capacity of the lymphatic system in the report of the International Society of Lymphology
(ISL) (Orhan et al. 2019).

In the literature, the incidence of secondary lymphedema after breast cancer treatment was $16 \%$, and when the data of the cohort studies were analyzed, this frequency increased to $21 \%$. Factors that increase the development of lymphedema after breast cancer treatment are axillary lymph node dissection, chemotherapy, radiotherapy, and infection in the incision site after the operation (Schmitz et al. 2009). A body mass index of 30 $\mathrm{kg} / \mathrm{m}^{2}$ and above is also a defined risk factor for 
lymphedema associated with breast cancer. The increase in body mass index causes physical activity and exercises not to be done regularly (Zhu et al. 2014).

Breast cancer-related lymphedema is one of the most stressful symptoms and one of the most common complications for individuals due to its prognosis (Sakorafas et al. 2006). Although improvements in treatment increase survival in breast cancer, shoulder dysfunction associated with upper extremity functions, upper extremity muscle weakness, and lymphedema are observed in patients after treatment (Lee et al., 2001, Radina et al. 2004; Gary, 2007; Büyükakıncak et al. 2014). Voogd et al. reported that women with lymphedema most frequently experience problems with the upper extremity (Voogd et al. 2003). Lymphedema that develops after breast cancer surgery often negatively affects the glenohumeral joint by increasing the tension in the tendons of the rotator cuff muscles and disrupting the scapulohumeral rhythm (Herrera \& Stubblefield, 2004). Moreover, lymphedema reduces upper extremity muscle strength and range of motion, may cause symptoms such as pain and fatigue, resulting in activity limitations and a decrease in upper extremity functional level (Taghian et al. 2014; Klernas et al. 2015). Decreases in muscle strength affect physical performance and decrease the level of independence in daily life (Khan et al. 2012; Fu, 2014).

There are studies in the literature examining the effects of lymphedema on upper extremity functionality, quality of life, disability, muscle weakness, and shoulder pain (Kwan et al. 2002; Beaulac et al., 2002, Ahmed et al., 2008, Atalay et al. 2011; Ridner, 2005). However, the effect of hand grip strength on activities of daily living has not been evaluated in studies. This study aimed to examine the relationship of hand grip strength with upper extremity functionality, activities of daily living, and physical activity level in female patients with lymphedema who had undergone breast cancer surgery. It was hypothesized that hand grip strength in lymphedema patients might be related to upper extremity function, activities of daily living, and physical activity level.

\section{MATERIALS AND METHODS}

\section{Ethics Approval}

The study protocol was approved by the Uskudar University Non-Invasive Ethics Committee (Decision number: 2020-80; Date: 29.01.2020). The participants were informed about the scope and procedures of the study. Written informed consent was obtained from all participants in line with the principles of the Declaration of Helsinki.

\section{Patients}

In this study, female patients between the ages of 30 and 70 years who were operated unilaterally for breast cancer and diagnosed with lymphedema associated with breast cancer treatment at Acibadem Maslak Hospital Senology Research Institute between February 2020 and December 2020, and those who volunteered to participate in the study were included in the study. Fifteen female patients who met the study criteria were included in the study group. Patients with bilateral lymphedema, patients with metastatic breast cancer, patients aged 70 years and older, patients with secondary shoulder problems in the affected arm, and existing upper extremity infections were excluded from the study.

Participants' demographic data (age, height, weight, body mass index) and detailed medical history (dominant and affected side, type of surgery, other cancer-related treatments, postoperative lymphedema onset time, and lymphedema duration) were recorded.

\section{Evaluation of Lymphedema}

For the diagnosis of upper extremity lymphedema on all participants, the circumference was measured with a standard tape measure, taking the anterior projection of the styloid process of the ulna as a reference, by marking the reference points at intervals of 10 centimeters $(\mathrm{cm})$ up to the axillary region. The severity of lymphedema was determined according to the values accepted by the American Physiotherapy Association (Taylor et al. 2006). If the difference between the extremities was less than $3 \mathrm{~cm}$, it was accepted as mild lymphedema, $3-5 \mathrm{~cm}$ as moderate, and greater than $5 \mathrm{~cm}$ as severe lymphedema (Karadibak et al. 2009). 
Table 1. Summary of patient characteristics

Patients with lymphedema after breast cancer surgery $(n=15)$

\begin{tabular}{|c|c|c|}
\hline & Mean \pm SD & (Min-Max) \\
\hline Age (years) & $51 \pm 10.60$ & $35-69$ \\
\hline Height (m) & $1.61 \pm 0.078$ & $1,48-1,76$ \\
\hline Weight (kg) & $74.16 \pm 13.87$ & $55-97$ \\
\hline BMI (kg/m²) & $28.60 \pm 5.47$ & $21.48-36.21$ \\
\hline $\begin{array}{l}\begin{array}{l}\text { Onset time of lymphedema } \\
\text { (months) }\end{array} \\
\end{array}$ & $24.33 \pm 54.07$ & $1-216$ \\
\hline $\begin{array}{l}\begin{array}{l}\text { Duration of Lymphedema } \\
\text { (months) }\end{array} \\
\end{array}$ & $25.13 \pm 73.26$ & $1-288$ \\
\hline Grip affected side (kgf) & $20.63 \pm 3.82$ & $16,6-28$ \\
\hline \multirow[t]{2}{*}{ Grip unaffected side (kgf) } & $20.55 \pm 4.71$ & $13.6-28.1$ \\
\hline & $\mathbf{n}$ & $\%$ \\
\hline \multicolumn{3}{|l|}{ Type of surgery } \\
\hline $\begin{array}{l}\text { Modified Radical Mastectomy } \\
\text { (MRM) }\end{array}$ & 7 & 46.6 \\
\hline Breast Conserving Surgery (BCS) & 4 & 26.7 \\
\hline $\begin{array}{l}\text { Breast Reconstruction Surgery } \\
\text { (BRS) }\end{array}$ & 4 & 26.7 \\
\hline \multicolumn{3}{|l|}{ Affected arm } \\
\hline Right & 5 & 33.3 \\
\hline Left & 10 & 66.7 \\
\hline \multicolumn{3}{|l|}{ Dominant hand } \\
\hline Right & 13 & 86.7 \\
\hline Left & 2 & 13.3 \\
\hline Chemotherapy & 14 & 93.3 \\
\hline Radiotherapy & 13 & 86.7 \\
\hline \multicolumn{3}{|l|}{ Lymphedema severity } \\
\hline Mild $(<3 \mathrm{~cm})$ & 7 & 46.7 \\
\hline Moderate $(3-5 \mathrm{~cm})$ & 5 & 33.3 \\
\hline Severe $(>5 \mathrm{~cm})$ & 3 & 20.0 \\
\hline
\end{tabular}

SD standart deviation; Min-Max minimum-maximum

\section{Evaluation of Hand Grip Strength}

Hand grip strength, in both hands in the standard position recommended by the "American Society of Hand Therapists"; was measured with a hand dynamometer (Saehan Corporation, Masan, Korea) with the elbow flexed to $90^{\circ}$ and the forearm and wrist in the neutral position. Before the measurements, the participants were informed verbally. When participants were ready, they were asked to grip the dynamometer with all their strength for 3 seconds and then release it. Each evaluation was repeated 3 times and averaged. Participants rested for 1 minute between measurements. A difference of $\geq 10 \%$ between the non-lymphedema and lymphedema sides was considered as a decrease in hand grip strength on the lymphedema side (Hladiuk et al. 1992).

\section{Disabilities of Arm, Shoulder and Hand Questionnaire (DASH)}

It is a 30-item self-report questionnaire consisting of three parts, developed to evaluate upper extremity functional status and musculoskeletal symptoms. Each item is scored on a 5-point Likert (1-5) scale. According to the survey, the smallest number 1 indicates 'no difficulty' and the highest number 5 'serious difficulties'. The total score of this questionnaire ranges from 0-100. An increase in score means worsening of functional status. When the results are calculated, the number ' 0 ' is considered 'no disability, while the number ' 100 ' is considered the 'most severe disability'. The total score is calculated as a percentage over 100 points, using the formula (Total score of marked items/number 
of marked items -1 ) $\times 25$. (Hudak et al. 1996; Gummesson et al. 2006). The Turkish validity and reliability study of the questionnaire was conducted (Düger et al. 2006).

\section{Milliken Activities of Daily Living Scale (MAS)}

MAS is a patient-centered assessment of activity limitation that measures upper extremity impairment. The questionnaire can be used in any disorder that results in upper extremity activity limitation. MAS provides scales that simultaneously measure "ability" and "necessity" for each item. MAS is a 47-item self-report questionnaire designed to include bilateral and unilateral tasks that require both gross and fine motor skills, in addition to varying grip patterns and resistance levels. This questionnaire covers the three main areas of The International Classification of Functioning (ICF) and is divided into six sections for clinical utility with the following task groups:

1. Preparing and eating food (8 items),

2. Personal care (9 items),

3. Dressing (8 items),

4. Object manipulation (9 items),

5. House cleaning and laundry (7 items),

6. Other Activities (6 items).

For each item, there is a 5-point scale to score the current skill level and a 3-point scale to score the requirement level. For each item, the ability level is scored first, followed by the requirement level. The total score for all sections is obtained by adding the current skill level points for each section. The total score ranges from 47-235. In the combined scoring procedure, each skill score is multiplied by the requirement score and the resulting scores are summed. This procedure results in 15 points for each item, with a combined total score of up to 705 (Seaton et al. 2005). A validity and reliability study of the questionnaire was conducted for the Turkish population (Akel et al. 2010).

\section{International Survey of Physical Activity (IPAQ)}

IPAQ is used to determine the physical activity levels of the patients. This questionnaire evaluates the severe, moderate activities and walking activities of the individuals in the last seven days. The long form evaluates activities in this area such as housework, gardening, work activity, transportation, and leisure activities in detail. Time spent sitting is recorded as weekdays and weekends.
There are two different evaluations in calculating the total score. The first includes specific scoring (work, transportation, gardening, leisure), and the second includes activity-specific scoring (walking, moderate activity, severe activity). A score is obtained in "metabolic equation (MET)-minutes". A MET-minute is calculated by multiplying the minute of activity performed by the MET score. MET-minute scores are based on kilocalories for a 60-kilogram person.

Weekly MET-minute (min) scores are calculated by multiplying the metabolic equation (MET) values corresponding to each activity (very severe physical activity $=8$ METs, severe physical activity $=6.0$ METs, moderate-severe physical activity $=5.5$ METs, moderate physical activity $=4.0$ METs, mild physical activity $=3.3$ METs), the duration of the activities ( $\mathrm{min}$ ) and the frequency (number of days) (Craig et al. 2003; Committee, 2005). The Turkish validity and reliability study of the questionnaire was conducted (Sağlam et al. 2012).

\section{Statistical Analysis}

The data obtained in the study were analyzed using the Statistical Package for Social Sciences (SPSS) Program version 26.0. The variables used in the study were expressed using percentage (\%), mean \pm standard deviation $(x \pm S D)$, and number. The normal distribution of the obtained numerical variable was determined visually (histogram and probability graphs) and analytical methods (Kolmogorov-Smirnov/Shapiro-Wilk Tests, Variation Coefficient Analysis). Numerical variables were shown as median and IQR (25-75), and categorical variables were shown as frequency and percentage (\%). The level of relationship between the two variables was evaluated with Spearman's correlation test. The results were accepted in a 95\% confidence interval and significance was accepted as $\mathrm{p}<0.05$.

\section{RESULTS}

The sociodemographic, physical, and clinical characteristics of the individuals participating in the study are shown in Table 1 . The mean age was $51 \pm 10.60$ years and the mean body mass index (BMI) was $28.60 \pm 5.47 \mathrm{~kg} / \mathrm{m}^{2}$. The mean duration of lymphedema development after the operation of the study group was $24.33 \pm 54.07$ months, and the duration of lymphedema was $25.13 \pm 73.26$ months. 
According to the lymphedema evaluation results, $46.7 \%(n=7)$ of the patients were classified as having mild lymphedema, 33.3\% $(\mathrm{n}=5)$ as moderate lymphedema, and $20.0 \%(\mathrm{n}=3)$ as severe lymphedema.

The upper extremity functionality, activities of daily living, and physical activity levels of the participants are shown in Table 2 . The mean value of the upper extremity functionality level of the patients was $39.33 \pm 19.11$. The mean total score of daily living activity was $493.13 \pm 57.48$. The mean total score of the physical activity levels of the patients was $681.06 \pm 538.85$.

Table.2. Mean scores of the scales

\begin{tabular}{lcc}
\hline & Mean \pm SD & Median (min-max) \\
\hline The upper extremity functionality & & $39.16(2.77-73.33)$ \\
DASH score & $39.33 \pm 19.11$ & $488(420-640)$ \\
\hline Activities of daily living & $493.13 \pm 57.48$ & $0(0-180)$ \\
Total MAS score & & $462(0-1848)$ \\
\hline Physical activity levels & $57 \pm 66.16$ & $568.5(0-1848)$ \\
IPAQ moderate activity & $554.4 \pm 499.45$ & $681.06 \pm 538.85$ \\
IPAQ walking & & \\
Total IPAQ score & &
\end{tabular}

Table 3 shows the correlation of hand grip strength with arm, shoulder, and hand problems, activities of daily living, and physical activity level in patients with lymphedema after breast cancer surgery. When the relationship between the scales was examined; there was no statistically significant difference between DASH score, total MAS score, and IPAQ scores ( $p>0.05)$. A good positive correlation was found between the hand grip strength of the affected side and the total MAS score (r: 0.609; p: 0.016). A negative correlation was found between the hand grip strength of the affected side and the DASH score (r: -0.624; p: 0.013).

A positive correlation was found between the development time of lymphedema after the operation and the coarse hand grip strength of the affected side (r: 0.574; p: 0.025). A weak positive correlation was found between the duration of postoperative lymphedema and the total MAS score (r: 0.766; p: 0.001). The relationship between the hand grip strength of the affected side and the hand grip strength of the unaffected side was statistically positively significant (r: 0.756 ; $\mathrm{p}$ : 0.001).

\section{DISCUSSION}

This study aimed to evaluate the relationship of hand grip strength with upper extremity functionality, daily living activities, and physical activity level in female patients who were operated on for unilateral breast cancer and developed secondary lymphedema. The primary finding of this study is that the affected side hand grip strength is associated with activities of daily living and upper extremity function.

Upper extremity dysfunctions after breast cancer surgery cause difficulties in the daily activities of individuals and negatively affect their quality of life. The most important of the upper extremity problems is lymphedema (Quiron, 2010; Beaulac et al. 2002). In a study, 30-50\% of breast cancer survivors had persistent arm and shoulder disorders, defined as limited shoulder mobility, lymphedema, and arm/shoulder pain (Lee et al. 2008). These problems encountered after breast cancer treatment mostly limit the activities of daily living in which the upper extremity is used (Brach et al. 2004). It has been reported in the literature that the prevalence of lymphedema in patients who underwent axillary dissection after breast cancer surgery varies between 6-30\% (Sclafani et al. 2008; DiSipio et al. 2013). 
Table 3. Correlation of hand grip strength with age(years), post-op lymphedema onset time, arm, shoulder, and hand problems and activities of daily living and physical activity level in patients with lymphedema after breast cancer

r: Spearman's correlation coefficient, $* \mathrm{p}<0.05, * * \mathrm{p}<0.01$.

\begin{tabular}{|c|c|c|c|c|c|c|c|c|c|c|}
\hline & & Age & $\begin{array}{c}\text { Postop } \\
\text { lymphedema } \\
\text { duration }\end{array}$ & $\begin{array}{l}\text { Hand grip } \\
\text { strength } \\
\text { affected } \\
\text { side }(\mathrm{kg})\end{array}$ & $\begin{array}{l}\text { Hand grip } \\
\text { strength } \\
\text { unaffected } \\
\text { side }(\mathrm{kg})\end{array}$ & $\begin{array}{l}\text { Total } \\
\text { MAS } \\
\text { Score }\end{array}$ & $\begin{array}{c}\text { DASH } \\
\text { Score }\end{array}$ & $\begin{array}{l}\text { IPAQ- } \\
\text { moderate } \\
\text { intensity } \\
\text { activities }\end{array}$ & $\begin{array}{c}\text { IPAQ- } \\
\text { walking }\end{array}$ & $\begin{array}{l}\text { IPAQ } \\
\text { Score }\end{array}$ \\
\hline \multirow[t]{2}{*}{ Age(years) } & $\mathrm{r}$ & 1 & $-0,008$ & $-0,431$ &,$- 641 * *$ & 0,391 &, $639 *$ & $-0,226$ & $-0,28$ & 0,292 \\
\hline & $\mathrm{p}$ & & 0,977 & 0,109 & 0,010 & 0,149 & 0,010 & 0,418 & 0,312 & 0,291 \\
\hline \multirow{2}{*}{$\begin{array}{l}\text { Postop } \\
\text { lymphedema } \\
\text { duration } \\
\end{array}$} & $\mathrm{r}$ & 0,008 & 1 &, $574^{*}$ & 0,429 &, $766^{* *}$ & $-0,465$ & $-0,171$ & 0,165 & 0,133 \\
\hline & $\mathrm{p}$ & 0,977 & & 0,025 & 0,111 & 0,001 & 0,081 & 0,543 & 0,558 & 0,637 \\
\hline \multirow{2}{*}{$\begin{array}{l}\text { Hand grip } \\
\text { strength } \\
\text { affected } \\
\text { side }(\mathrm{kg}) \\
\end{array}$} & $\mathrm{r}$ & 0,431 &, $574^{*}$ & 1 &, $756^{* *}$ &, $609^{*}$ &,$- 624^{*}$ & $-0,225$ & 0,109 & 0,012 \\
\hline & $\mathrm{p}$ & 0,109 & 0,025 & & 0,001 & 0,016 & 0,013 & 0,421 & 0,698 & 0,966 \\
\hline \multirow{2}{*}{$\begin{array}{l}\text { Hand grip } \\
\text { strength } \\
\text { unaffected } \\
\text { side }(\mathrm{kg}) \\
\end{array}$} & $\mathrm{r}$ &, $641^{* *}$ & 0,429 &, $756^{* *}$ & 1 &, $580^{*}$ & $-0,464$ & $-0,222$ & 0,305 & 0,264 \\
\hline & $\mathrm{p}$ & 0,010 & 0,111 & 0,001 & & 0,023 & 0,082 & 0,427 & 0,269 & 0,342 \\
\hline \multirow{2}{*}{$\begin{array}{l}\text { Total MAS } \\
\text { score }\end{array}$} & $\mathrm{r}$ & 0,391 &, $766^{* * *}$ &, $609^{*}$ &, $580^{*}$ & 1 &,$- 575^{*}$ & 0,103 & 0,025 & 0,105 \\
\hline & $\mathrm{p}$ & 0,149 & 0,001 & 0,016 & 0,023 & & 0,025 & 0,714 & 0,930 & 0,710 \\
\hline \multirow[t]{2}{*}{ DASH score } & $\mathrm{r}$ &, $639^{*}$ & $-0,465$ &,$- 624^{*}$ & $-0,464$ &,$- 575^{*}$ & 1 & $-0,210$ & $-0,157$ & 0,176 \\
\hline & $\mathrm{p}$ & 0,010 & 0,081 & 0,013 & 0,082 & 0,025 & & 0,453 & 0,577 & 0,529 \\
\hline \multirow{2}{*}{$\begin{array}{l}\text { IPAQ- } \\
\text { moderate } \\
\text { intensity } \\
\text { activities }\end{array}$} & $\mathrm{r}$ & 0,226 & $-0,171$ & $-0,225$ & $-0,222$ & 0,103 & $-0,210$ & 1 & $-0,145$ & 0,192 \\
\hline & $\mathrm{p}$ & 0,418 & 0,543 & 0,421 & 0,427 & 0,714 & 0,453 & & 0,606 & 0,493 \\
\hline \multirow[t]{2}{*}{ IPAQ-walking } & $\mathrm{r}$ & 0,280 & 0,165 & 0,109 & 0,305 & 0,025 & $-0,157$ & $-0,145$ & 1 &, $918^{* *}$ \\
\hline & $\mathrm{p}$ & 0,312 & 0,558 & 0,698 & 0,269 & 0,930 & 0,577 & 0,606 & & 0,000 \\
\hline \multirow[t]{2}{*}{ IPAQ Score } & $\mathrm{r}$ & 0,292 & 0,133 & 0,012 & 0,264 & 0,105 & $-0,176$ & 0,192 & $918^{* * *}$ & 1 \\
\hline & $\mathrm{p}$ & 0,291 & 0,637 & 0,966 & 0,342 & 0,710 & 0,529 & 0,493 & 0,000 & \\
\hline
\end{tabular}

BMI, body mass index; MAS, Milliken Activities Of Daily Living Scale; DASH, Disabilities of Arm, Shoulder and Hand; IPAQ, International Physical Activity Questionnaire

Lymphedema results in decreased shoulder range of motion (12-32\%), pain (12-51\%), and muscle weakness (18-23\%) (Shamley et al. 2012; Collins. 2004). Lymphedema, which is a chronic and progressive disease, causes a significant decrease in the quality of life due to its prognosis
(Karki et al. 2005; Schmitz et al. 2012). Thus, the incidence of chronic upper extremity morbidity increases (Keramopoulos et al. 1993).

The prevalence of impaired hand grip strength in the arm with lymphedema was investigated in several studies (Liu et al., 2009, 
Rietman et al. 2006; Kootstra et al. 2010; Ververs et al. 2001). It is very important to consider the inherent difference (about 10\%) between the dominant and non-dominant extremity when assessing hand grip strength (Petersen et al. 1989). In one study, muscle weakness was found in the arm with lymphedema compared to the unaffected side in 36\% of the subjects (Petersen et al. 1989). In a prospective study involving 2.5 years of follow-up after breast cancer surgery, a significant reduction in hand grip strength (11\%) was observed on both the affected and unaffected sides (Sagen et al. 2014). It has been reported that the hand dynamometer is reliable and evaluates the general function in breast cancer patients (Cantarero- Villanueva et al. 2012; Kim et al. 2014). In the study of Rietman et al., it was reported that there was a significant decrease of $3.4 \mathrm{~kg}$ in hand grip strength two years after sentinel lymph node biopsy of the patients (Rietman et al. 2006). In another study, axillary lymph node dissection was found to cause more weakness than sentinel lymph node biopsy (Sagen et al. 2014). Research findings in our study support the literature. Patients were found to have lower hand grip strength on the affected arm. Many of our patients are hesitant to use their affected arm, which often results in muscle atrophy, weakness, and functional limitations (Lee et al. 2015).

In the study of Korucu et al., published in 2020, in which 107 patients who underwent breast cancer surgery and axillary lymph node dissection were evaluated, the DASH score of patients with lymphedema was 35.83 , while this value was found 26.66 in patients without lymphedema (Korucu et al. 2020). In our study, it was found that patients with MRM had higher DASH scores than the ones that underwent other types of surgery and therefore, they had less upper extremity function. In this article, the relationship between the hand grip strength of the affected side, activities of daily living, and upper extremity functionality was found to be significant. Decreased hand grip strength on the affected side causes a decrease in the level of physical activity in the upper extremity and limitations in daily living movements. In our study, a significant correlation was found between the DASH score and another variable, age. In a study, it was found that older patients had a decrease in shoulder range of motion and hand grip strength (Swenson et al. 2002; Fleissig et al. 2006). In our study, it was found that the hand grip strength of the affected side was better in patients with a later development time of lymphedema after the operation. In our cases, it was thought that the quality of life and upper extremity functionality increased due to the decrease in the side effects of chemotherapy and radiotherapy over time.

In many studies in the literature, it has been found that a body mass index higher than $25 \mathrm{~kg} / \mathrm{m}^{2}$ increases the difficulty of daily living activities in patients (Kootstra et al. 2010; Karki et al. 2005). In our study, it was found that all patients with severe lymphedema had a BMI higher than $25 \mathrm{~kg} / \mathrm{m}^{2}$. This result supports the literature. Therefore, postoperative weight control is important.

Regular physical activity and exercise have positive effects on breast cancer patients during and after treatment. These include treatmentrelated side effects, such as fatigue (Kangas et al. 2008), gastrointestinal symptoms (Winningham \& MacVicar, 1988), and emotional problems (Duijts et al. 2011). In addition, regular exercise has positive effects such as increased cardiopulmonary capacity, muscle strength (Furmaniak et al. 2016), improved immune function (Fairey et al. 2002), and improved survival rates (Chen et al. 2011). Despite these beneficial effects, a decrease in physical activity level has been reported in patients with breast cancer after diagnosis (Irwin et al. 2003). Regular exercise has become an important approach to alleviate these side effects. In one study, it was reported that exercise improved the use of muscle pumps in patients with lymphedema after breast cancer surgery and, accordingly, increased the stimulation of lymphatic transport (Gebruers et al. 2017). In addition, physical activity level was found to be a risk factor in the increase of functional problems in daily living activities in patients who developed lymphedema after breast cancer surgery (De Vrieze et al. 2020). Therefore, it is important to encourage patients to reach an adequate level of physical activity. In our study, more than half of the patients were at the inactive level (<600 MET-min/week), and there 
were no moderate or severe activities in the sufficiently active category. In addition, no relationship was found between hand grip strength and physical activity level. Further studies with more patients may be needed to investigate this relationship.

In conclusion, hand grip strength, upper extremity functionality, and physical activity levels should be evaluated in the early follow-up and treatment planning of patients undergoing breast cancer surgery. In a study, it was stated that it benefited the development of hand grip strength capacity, general muscle strength, endurance and flexibility (Kümmel et al. 2016; Dourado et al. 2006). In the literature, studies on exercise are becoming more common in patients who develop lymphedema due to breast cancer. It is known that exercise improves the quality of life, general physical fitness, and upper extremity function and reduces fatigue (Kilbreath et al. 2012; Herrero et al. 2006; Hayes et al. 2013). The effects of exercise on reducing the volume of lymphedema have also been reported in a few studies (Kim et al. 2010). In a study evaluating scapular dyskinesia after breast cancer surgery, it was stated that there were significant differences between the upper extremities of patients with shoulder pain after treatment and that starting exercises that increase scapular control may be effective in preventing shoulder pain and/or dysfunction (Sayaca and Simsek, 2020). Considering these results, it was concluded that improving hand grip strength in the early period and adding hand grip strength exercises to the treatment program would increase upper extremity functionality and quality of life in these patients. Finally, it is thought that there is a need for studies comparing the effectiveness of exercises for hand grip strength before and after surgery.

This study has some limitations: (i) the low number of patients, (ii) the lack of normal distribution on lymphedema onset time and duration of lymphedema measurements, (iii) the absence of a control group, and (iv) the lack of the evaluation of different sides of the hands (dominant and non-dominant). Also, the fact that the patients were not evaluated before surgery may be a limitation. There is a need for new studies in which more patients are evaluated before and after surgery and followed up for a longer-term.

\section{Conflict of interests}

The authors have no conflict of interests to declare. No financial support was received for this study.

\section{Ethics Statement}

The studies involving human participants were reviewed and approved by the Uskudar University Non-Invasive Ethics Committee (Date: 29.01.2020; Decision / Protocol number: 2020-80). Written informed consent to participate in this study was provided by the patients/participants.

\section{REFERENCES}

Ahmed, RL., Prizment, A., Lazovich, D., Schmitz, KH., Folsom, AR. (2008). Lymphedema and quality of life in breast cancer survivors: the Iowa Women's Health Study. J Clin Oncol;26(35):5689-5696.

Akel, BS., Oksuz, C., Kayihan, H. (2010). Adaptation and validation of Turkish version of the Milliken ADL Scale (MAS). Journal of Hand Therapy; 23: e12.

Atalay, NŞ., Taflan Selçuk, S., Ercidoğan, Ö. ve ark. (2011). The presence of upper extremity problems and the effect on quality of life in breast cancer patients who undergone breast surgery and axillary dissection. Turk $J$ Phys Med Rehab; 57:186-192.

Beaulac, SM., McNair, LA., Scott, TE., LaMorte, WW., Kavanah, MT. (2002). Lymphedema and quality of life in survivors of early-stage breast cancer. Arch Surg;137(11):1253-1257.

Brach, M., Cieza, A., Stucki, G., et al. (2004). ICF core sets for breast cancer. J Rehabil Med; (44 Suppl): 121-127.

Büyükakıncak, Ö., Akyol, Y., Özen, N. ve ark. (2014). Quality of Life in Patients with Breast Cancer at Early Postoperative Period: Relationship to Shoulder Pain, Handgrip Strength, Disability, and Emotional Status. Turk J Phys Med Rehab; 60:1-6.

Cantarero-Villanueva, I., Fernandez-Lao, C., DiazRodriguez, L., Fernandez-deLas-Penas, C., Ruiz, JR., Arroyo-Morales, M. (2012). The handgrip strength test as a measure of function in breast cancer survivors: relationship to cancer-related symptoms and physical and physiologic parameters. Am J Phys Med Rehabilitation; 91(9):774e82. 
Chen, X., Lu, W., Zheng, W., Gu, K., Matthews, CE., Chen, Z., Zheng, Y., Shu, XO. (2011). Exercise after diagnosis of breast cancer in association with survival. Cancer Prev Res (Phila); 4(9):1409-1418.

Collins, LG. (2004). Perceptions of upper-body problems during recovery from breast cancer treatment. Supportive Care in Cancer; 106113.

Committee, I.R., (2005). Guidelines for data processing and analysis of the International Physical Activity Questionnaire (IPAQ) short and long forms. Retrieved September. 17:2008.

Craig, C. L., Marshall, A. L., Sjostrom, M., Bauman, A. E., Booth, M. L., Ainsworth, B. E., Pratt, M., Ekelund, U., Yngve, A., Sallis, J. F., \& Oja, P. (2003). International Physical Activity Questionnaire: 12-country reliability and validity. Medicine \& Science in Sports \& Exercise, 35, 1381-1395.

De Vrieze, T., Gebruers, N., Nevelsteen, I., Tjalma, WAA., Thomis, S., De Groef, A., Dams, L., Van der Gucht, E., Devoogdt, N. (2020). Physical activity level and age contribute to functioning problems in patients with breast cancer-related lymphedema: a multicentre cross-sectional study. Support Care Cancer: off J Multinatl Assoc Support Care Cancer. https://doi.org/10.1007/s00520-020-05375-3

DiSipio, T., Rye, S., Newman, B., Hayes, S. (2013). Incidence of unilateral arm lymphoedema after breast cancer: a systematic review and metaanalysis. Lancet Oncol;14(6):500-15.

Dourado, V. Z., Antunes, L. C., Tanni, S. E., de Paiva, S. A., Padovani, C. R. \& Godoy, I. (2006). Relationship of upper-limb and thoracic muscle strength to 6-min walk distance in COPD patients. Chest; 129 (3), 551-557.

Düger, T., Yakut, E., Öksüz, Ç., Yörükan, S., Bilgütay, BS., Ayhan, Ç., Leblebicioğlu, G., Kayıhan, H., Kırdı, N., Yakut, Y., Güler, Ç. (2006). Reliability and validity of the Turkish version of the Disabilities of the Arm. Shoulder and Hand (DASH) Questionnaire. Turk J Phys Med Rehab; 17(3): 99-107.

Duijts, SF., Faber, MM., Oldenburg, HS., van Beurden, M., Aaronson, NK. (2011).
Effectiveness of behavioral techniques and physical exercise on psychosocial functioning and health-related quality of life in breast cancer patients and survivors-a meta-analysis. Psychooncology; 20(2):115126.

Fairey, AS., Courneya, KS., Field, CJ., Mackey, JR. (2002), Physical exercise and immune system function in cancer survivors: a comprehensive review and future directions. Cancer; 94(2):539-551.

Fleissig, A., Fallowfield, LJ., Langridge, CI., Johnson, L., Newcombe, RG., Dixon, JM., et al. (2006). Post-operative arm morbidity and quality of life. Results of the ALMANAC randomised trial comparing sentinel node biopsy with standard axillary treatment in the management of patients with early breast cancer. Breast Cancer Res Treat; 95(3):279e93.

$\mathrm{Fu}$, MR. (2014). Breast cancer-related lymphedema: symptoms, diagnosis, risk reduction, and management. World J Clin Oncol;5(3):241-7.

Furmaniak, AC., Menig, M., Markes, MH. (2016). Exercise for women receiving adjuvant therapy for breast cancer. Cochrane Database Syst Rev; 9(9): Cd005001.

Gary, DE. (2007). Lymphedema diagnosis and management. J Am Acad Nurse Pract. 2007; 19(2):72-78.

Gebruers, N., Verbelen, H., De Vrieze, T., Vos, L., Devoogdt, N., Fias, L., Tjalma, W. (2017). Current and future perspectives on the evaluation, prevention and conservative management of breast cancer related lymphoedema: a best practice guideline. Eur J Obstet Gynecol Reprod Biol; 216:245-253.

Gummesson, C., Ward, MM., Atroski, I. (2006). The shortened disabilities of the arm shoulder and hand questionnaire (QuickDASH): validity and reliability based on responses within the full- length DASH. BMC Musculoskelet Disord; 7:44.

Hayes, SC., Battistutta, D., Parker, AW., Hirst, C., Newman, B. (2005). Assessing task "burden" of daily activities requiring upper body function among women following breast cancer treatment. Support Care Cancer; 13: 255- 265.

Hayes, SC., Rye, S., Disipio, T., Yates, P., Bashford, J., Pyke, C., Saunders, C., 
Battistutta, D., Eakin, E. (2013). Exercise for health: a randomized, controlled trial evaluating the impact of a pragmatic, translational exercise intervention on the quality of life, function and treatmentrelated side effects following breast cancer. Breast Cancer Res Treat; 137:175-186.

Herrera, JE., Stubblefield, MD. (2004). Rotator cuff tendonitis in lymphedema: a retrospective case series. Arch Phys Med Rehabil;85(12):1939-42.

Herrero, F., San Juan, AF., Fleck, SJ., Balmer, J., Perez, M., Canete, S., Earnest, CP., Foster, C., Lucia, A. (2006). Combined aerobic and resistance training in breast cancer survivors: A randomized, controlled pilot trial. Int $J$ Sports Med; 27:573-580.

Hladiuk, M., Huchcroft, S., Temple, W., Schnurr, BE. (1992). Arm function after axillary dissection for breast cancer: a pilot study to provide parameter estimates. J Surg Oncol; 50:47-52.

Hudak, PL., Amadio, PC., Bombardier, C. (1996). Development of an upper extremity outcome measure: The DASH (Disabilities of the Arm Shoulder and Hand). Am J Indust Med;29: 602-8

Irwin, ML., Crumley, D., McTiernan, A., Bernstein, L., Baumgartner, R., Gilliland, FD., Kriska, A., Ballard-Barbash, R. (2003). Physical activity levels before and after a diagnosis of breast carcinoma: the Health, Eating, Activity, and Lifestyle (HEAL) study. Cancer; 97(7):1746- 1757.

Kangas, M., Bovbjerg, DH., Montgomery, GH. (2008). Cancer-related fatigue: a systematic and meta-analytic review of nonpharmacological therapies for cancer patients. Psychol Bull; 134(5):700-741.

Karadibak, D., Yıldırım, Y., Kara, B., Saydam, S. (2009). Effect of complex decongestive therapy on upper extremity lymphedema. Fizyoter Rehabil;20(1):03- 08.

Karki, A., Simonen, R., Malkia, E., Selfe, J. (2005). Impairments, activity limitations and participation restrictions 6 and 12 months after breast cancer operation. J Rehabil Med; 37(3):180e8.

Keramopoulos, A., Tsionou, C., Minaretzis, D., Michalas, S., Aravantinos, D. (1993). Arm morbidity following treatment of breast cancer with total axillary dissection: A multivariated approach. Oncol; 50(6): 445449

Khan, F., Amatya, B., Pallant, JF., Rajapaksa, I. (2012). Factors associated with long-term functional outcomes and psychological sequelae in women after breast cancer. Breast;21(3):314-20.

Kilbreath, SL., Refshauge, KM., Beith, JM., Ward, LC., Lee, M., Simpson, JM., Hansen, R. (2012). Upper limb progressive resistance training and stretching exercises following surgery for early breast cancer: a randomized controlled trial. Breast Cancer Res Treat; 133:667-676.

Kim do S., Sim, YJ., Jeong HJ., Kim GC. (2010). Effect of active resistive exercise on breast cancer-related lymphedema: a randomized controlled trial. Arch Phys Med Rehabil; 91:1844-1848.

Kim, JK., Park, MG., Shin, SJ. (2014). What is the minimum clinically important difference in grip strength? Clin Orthop Relat Res; 472(8):2536e41.

Klernas, P., Johnsson, A., Horstmann, V., Kristjanson, LJ., Johansson, K. (2015). Lymphedema Quality of Life Inventory (LyQLI)-Development and investigation of validity and reliability. Qual Life Res;24(2):427-39.

Kootstra, JJ., Hoekstra-Weebers, JE., Rietman, JS., de Vries, J., Baas, PC., Geertzen, JH., et al. (2010). A longitudinal comparison of arm morbidity in stage I-II breast cancer patients treated with sentinel lymph node biopsy, sentinel lymph node biopsy followed by completion lymph node dissection, or axillary lymph node dissection. Ann Surg Oncol; 17(9):2384e94.

Korucu, TS., Ucurum, SG., Tastaban, E., Ozgun, H., Kaya, DO. (2020). Comparison of Shoulder-Arm Complex Pain, Function, and Scapular Dyskinesia in Women With and Without Unilateral Lymphedema After Breast Cancer Surgery. Clin Breast Cancer; Oct 29:S1526-8209(20)30267-6.

Kümmel J, Kramer A, Giboin LS, Gruber M. (2016). Specificity of balance training in healthy individuals: a systematic review and meta-analysis. Sports Med. Sep;46(9):126171.

Kwan, W., Jackson, J., Weir, LM., Dingee, C., McGregor, G., Olivotto, IA. (2002). Chronic 
arm morbidity after curative breastcancer treatment: prevalence and impact on quality of life. J Clin Oncol;20(20):4242-4248.

Lee, D., Hwang, JH., Chu, I., Chang, HJ., Shim, YH., Kim, JH. (2015). Analysis of factors related to arm weakness in patients with breast cancer-related lymphedema. Support Care Cancer. 2015 Aug;23(8):2297-304.

Lee, TS., Kilbreath, SL., Refshauge, KM., Beith, JM., Harris, LM. (2008). Prognosis of the upper limb following surgery and radiation for breast cancer. Breast Cancer Res Treatment;110:19-37.

Lee, Y., Mak, S., Tse, S., Chan, S. (2001). Lymphedema care of breast cancer patients in a breast care a. clinic: a survey of knowledge and health practise. Support Care Cancer; 9(8): 634-641.

Liu, CQ., Guo, Y., Shi, JY., Sheng, Y. (2009). Late morbidity associated with a tumournegative sentinel lymph node biopsy in primary breast cancer patients: a systematic review. Eur J Cancer (Oxford, Engl 1990);45(9):1560e8.

Orhan, C., Ozgul, S., Nakip, G., Baran, E., Uzelpasac1, E., Çinar, GN., Aksoy, S., Akbayrak, T. (2019). Effect of Lymphedema Severity on Quality of Life, Upper Limb Function, and Physical Activity Level in Patients with Breast Cancer Treatmentrelated Lymphedema. Anadolu Klin; 24 (3).

Petersen, P., Petrick, M., Connor, H., Conklin, D. (1989). Grip strength and hand dominance: challenging the $10 \%$ rule. Am J Occup Ther; 43: 444-447

Quiron, E. (2010). Recognizing and treating upper extremity lymphedema in postmastectomy/lumpectomy patients: A guide for primary care providers. J Am Acad Nurse Pract;22(9):450-459

Radina, E., Armer, J., Culbertson, S., Dusold, J. (2004). Post-breast cancer lymphedema: understanding women's knowledge of their condition. Oncol Nurs Forum;31(1):97-104.

Ridner, SH. (2005). Quality of life and a symptom cluster associated with breast cancer treatment-related lymphedema. Support Care Cancer;13(11):904-911.

Rietman, JS., Geertzen, JH., Hoekstra, HJ., Baas, P., Dolsma, WV., de Vries, J., et al. (2006). Long term treatment related upper limb morbidity and quality of life after sentinel lymph node biopsy for stage I or II breast cancer. Eur J Surg Oncol; 32(2): 148e52.

Sagen, A., Kaaresen, R., Sandvik, L., Thune, I., Risberg, MA. (2014). Upper limb physical function and adverse effects after breast cancer surgery: a prospective 2.5-year follow-up study and preoperative measures. Arch Phys Med Rehabil;95:875-881

Sağlam, M., Arıkan, H., Savcı, S., Inal-İnce, D., Boşnak- Güçlü, M., Karabulut, E. (2012). International physical activity questionnaire: reliability and validity of the Turkish version. Perceptual and Motor Skills. 111,278-284.

Sakorafas, GH., Peros, G., Cataliotti, L., Vlastos, G. (2006). Lymphedema following axillary lymph node dissection for breast cancer. Surg Oncol; 15:153-65.

Sayaca, Ç., Simsek, M. (2020). Scapular Dyskinesia After Modified Radical Mastectomy Surgery and Breast Conserving Surgery. Hacettepe University Faculty of Health Sciences Journal; 7(3), 310-323.

Schmitz, KH., Speck, RM., Rye, SA., DiSipio, T., Hayes, SC. (2012). Prevalence of breast cancer treatment sequelae over 6 years of follow-up: the Pulling Through Study. Cancer;118(8 Suppl):2217-25.

Schmitz, KH., Troxel, AB., Cheville, A., Grant, LL., Bryan, CJ., Gross, CR., ve ark. (2009). Physical Activity and Lymphedema (the PAL trial): assessing the safety of progressive strength training in breast cancer survivors. Contemp Clin Trials;30(3):23345.

Sclafani, LM., Baron, RH. (2008). Sentinel lymph node biopsy and axillary dissection: added morbidity of the arm, shoulder and chest wall after mastectomy and reconstruction. Cancer J;14(4):216-22.

Seaton, MK., Groth, GN., Matheson, L., Feely, C. (2005). Reliability and validity of the Milliken Activities of Daily Living Scale. $J$ Occup Rehabil; 15:343-51.

Shamley D, Lascurain-Aguirrebeña I, Oskrochi R, Srinaganathan R. (2012). Shoulder morbidity after treatment for breast cancer is bilateral and greater after mastectomy. Acta Oncol; 51(8):1045-1053.

Swenson, KK., Nissen, MJ., Ceronsky, C., Swenson, L., Lee, MW., Tuttle, TM. (2002). Comparison of side effects between sentinel 
lymph node and axillary lymph node dissection for breast cancer. Ann Surg Oncol; 9(8):745e53

Taghian, NR., Miller, CL., Jammallo, LS., O'Toole, J., Skolny, MN. (2014). Lymphedema following breast cancer treatment and impact on quality of life: a review. Crit Rev Oncol Hematol;92(3):22734.

Taylor, R., Jayasinghe, UW., Koelmeyer, L., et al. (2006). Reliability and validity of arm volume measurements for assessment of lymphedema. Phys Ther; 86:205-214.

Ververs, JM., Roumen, RM., Vingerhoets, AJ., Vreugdenhil, G., Coebergh, JW., Crommelin, MA., et al. (2001). Risk, severity and predictors of physical and psychological morbidity after axillary lymph node dissection for breast cancer. Eur $J$ Cancer; 37(8):991e9.

Voogd, AC., Ververs, JM., Vingerhoets, AJ., Roumen, RM., Coebergh, JW., Crommelin, MA. (2003). Lymphoedema and reduced shoulder function as indicators of quality of life after axillary lymph node dissection for invasive breast cancer. Br J Surg;90(1):7681.

Winningham, ML., MacVicar, MG. (1988). The effect of aerobic exercise on patient reports of nausea. Oncol Nurs Forum; 15(4):447450.

Zhu, YQ., Xie, YH., Liu, FH., Guo, Q., Shen, PP., Tian, Y. (2014). Systemic analysis on risk factors for breast cancer related lymphedema. Asian Pac J Cancer Prev; 15:6535-41.

How to cite this article: Ucel, O., Eyüboglu, F. and Celiker, R. (2021). Relationship of Hand Grip Strength on The Upper Extremity Function, Activities of Daily Living and Physical Activity Level in Patients with Postmastectomy Lymphedema: A Pilot Study. Int J Disabil SportsHealth Sci;4(2):140151.https://doi.org/10.3343 /ijdshs. 982589 